\title{
Learning to swallow together: Medical and speech and language therapy student interprofessional learning about dysphagia
}

\author{
Helen Kelly ${ }^{\mathrm{a}, *}$, Maireád Cronin ${ }^{\mathrm{a}}$, Helen Hynes ${ }^{\mathrm{b}}$, Sarah Duxbury ${ }^{\mathrm{a}}$ and Orlaith Twomey ${ }^{\mathrm{a}}$ \\ ${ }^{a}$ Department of Speech and Hearing Sciences, School of Clinical Therapies, University College Cork, Cork, \\ Republic of Ireland \\ ${ }^{\mathrm{b}}$ School of Medicine, University College Cork, Cork, Republic of Ireland
}

Received 11 June 2021

Accepted 1 September 2021

\begin{abstract}
.
BACKGROUND: Interprofessional education (IPE) is considered to be a necessary step in preparing the healthcare workforce for collaborative patient care. Dysphagia, a complex health condition, requires collaboration between disciplines such as medicine (MED) and speech and language therapy (SLT). Therefore, both disciplines must have a shared understanding of dysphagia management within the context of interprofessional care.

OBJECTIVE: This study investigated MED and SLT students' shared learning about dysphagia management following an IPE workshop. The student experience of IPE was also explored.

METHODS: Fifty students participated in one 3-hour classroom-based IPE dysphagia workshop which was appraised through a questionnaire completed immediately before and following the workshop. Within- and Between-Group analysis evaluated change in knowledge about dysphagia management. Comments related to student learning experiences were examined using a qualitative description approach.

RESULTS: $98 \%$ of students (24 MED; 25 SLT) completed pre- and post-workshop questionnaires. Wilcoxon SignedRank tests indicated statistically significant post-workshop growth in knowledge of symptoms $(p<0.001)$ and medical conditions $(p<0.001)$ related to dysphagia. Students reported increased confidence in their ability to identify dysphagia $(p<0.001)$. Greater understanding of interprofessional roles was observed post-workshop, notably nursing $(p<0.05)$, pharmacy $(p<0.05)$, occupational therapy $(p<0.05)$ and physiotherapy $(p<0.001)$. While recognised as beneficial to shared learning and appreciation of different discipline perspectives, both cohorts found IPE challenging.

CONCLUSIONS: Classroom-based IPE is an appropriate approach for shared learning about complex health conditions which require interprofessional care. Including patient-facing activities would further enhance student learning. While students found IPE challenging, they identified several benefits related to their professional development.
\end{abstract}

Keywords: Inter-professional education, inter-professional learning, IPE, dysphagia, speech and language therapy, medicine

${ }^{*}$ Corresponding author: Dr Helen Kelly, Department of Speech \& Hearing Sciences, School of Clinical Therapies, Brookfield Health Sciences Complex, University College Cork, Cork, T12 EK59, Republic of Ireland. E-mail: helen.kelly@ucc.ie. ORCID: 0000-0003-3694-2086

\section{Introduction}

The value of interprofessional education (IPE) has been recognised by the World Health Organisation in the context of international concerns around fragmented healthcare provision (WHO, 2010). Its 
"Framework for Interprofessional Education and Collaboration", recognises IPE as a "necessary step in preparing a 'collaborative practice-ready' health workforce" required for effective interprofessional healthcare collaboration (WHO, 2010, p.7).

Core IPE competencies have been identified (Interprofessional Education Collaborative Expert Panel, 2011) and a commitment to the inclusion of IPE in healthcare professions (HCP) education standards and programme accreditation is emerging (Azzam et al., 2021; CORU, 2018; Health and Care Professions Council, 2017). However, core curricula and frameworks are less well defined and a definitive set of learning outcomes applicable across all health professions is needed (O'Keefe et al., 2017; Steven et al., 2017). Recently, Steven et al. (2017) mapped the outcomes and standards required by five UK HCP regulatory bodies and proposed a framework for use by educators to plan and deliver meaningful IPE: "Knowledge for practice", "Skills for practice", "Patient-centred approach", "Ethical approach to practice", "Continuing professional development", "Team-working", and "Professionalism". Furthermore, O'Keefe et al. (2017) identified eight competency statements related to IPE that every entry-level HCP graduate should meet. Competencies include the ability to explain HCP roles to all involved in patient care, express professional opinions without discipline jargon, resolve patient care disagreements and welcome the exchange of instructive feedback, identify opportunities to involve other HCPs in goal setting and patient priorities, and critically evaluate interprofessional protocols and practices (O'Keefe et al., 2017).

Several systematic reviews have evaluated the attitudes of healthcare students towards IPE. BergerEstilita et al. (2020) found more than 50\% of their included studies demonstrated a significant increase in positive attitudes towards IPE by students following an IPE experience. Findings suggest that following IPE attitudes and perceptions of each other's profession improves (Reeves et al., 2016; Spaulding et al., 2019) with a significant improvement in collaborative knowledge and skills (Reeves et al., 2016) and behaviour (Spaulding et al., 2019). From a healthcare perspective, Reeves et al. (2016) report limited but growing evidence purporting the benefits of IPE to patients. Though more evidence is required, IPE has shown promising results in improving patient health outcomes (Oosterom et al., 2019; Shrader et al., 2018) and patient satisfaction (Oosterom et al., 2019).
Educating towards a 'collaborative practice-ready health workforce' is particularly critical for complex health conditions that require an interprofessional approach. Dysphagia (difficulty moving food/fluids from the lips to the stomach) is one such health condition. While difficult to estimate how many people experience dysphagia, it is highly prevalent in three main populations (Clavé \& Shaker, 2015): Neurogenic diseases, for example, Stroke (Aoki et al., 2016; Martino et al., 2005), Parkinson's Disease (Kalf et al., 2012; Suttrup \& Warnecke, 2016), and Dementia (Ikeda et al., 2002), Head-and-Neck cancer (Frowen et al., 2020), and the elderly (Baijens et al., 2016; Cabre et al., 2010). Poorly managed dysphagia can result in patient health deterioration, extended hospital stays, poor quality of life, aspiration pneumonia and death (Baijens et al., 2016; Clavé \& Shaker, 2015).

Dysphagia is not a distinct medical speciality and therefore requires the expertise of several HCPs, such as, Otorhinolaryngologists, SLTs and other medical specialists to take an interprofessional management approach (Clavé \& Shaker, 2015; Farpour et al., 2019). Dysphagia-related health outcomes are thought to improve with effective interprofessional involvement (Aoki et al., 2016; Middleton et al., 2011; WHO, 2010). However, HCP knowledge about dysphagia is inconsistent and sometimes lacking (Anderle et al., 2018; Farpour et al., 2019). Therefore, to optimise patient care, it is essential that HCPs have sufficient understanding of dysphagia and awareness of other HCPs involved in its management.

Two core professions involved in dysphagia management include medical doctors (MED) and speech and language therapists (SLT). However, while SLTs graduate with a proficiency in dysphagia management, dysphagia is often limited or omitted from medical curricula (Clavé \& Shaker, 2015). Several studies have explored IPE with MED and other HCP students, for example, dietetics (Nisbet et al., 2008; Shrader et al., 2018), nursing (Burford et al., 2020; Shrader et al., 2018), occupational therapy (Nasir et al., 2017; Shrader et al., 2018), pharmacy (Shrader et al., 2018; Wheeler et al., 2019), and SLT (Nasir et al., 2017; Nisbet et al., 2008). While IPE experiences have been explored, to our knowledge, none have included the assessment of shared learning about a health condition which requires interprofessional management by both disciplines once qualified. Endeavouring to align with recommended IPE framework (Steven et al., 2017) and competencies (O'Keefe et al., 2017), this bi-disciplinary 
workshop aspired to provide the opportunity for shared learning about dysphagia management, facilitate an appreciation and understanding of each discipline's expertise, and equip students to work effectively within interprofessional teams when qualified. The aims of this study were therefore to investigate the shared learning of MED and SLT students about dysphagia and the roles of HCPs involved in its management, following an IPE workshop. The advantages, benefits, and challenges of IPE from the student perspective were also explored.

\section{Methods}

\subsection{Participants}

This study employed a pre-post, mixed-methods, quasi-experimental design to explore the learning of undergraduate SLTs (entering their penultimate year) and undergraduate/ graduate entry MEDs (entering their final year), following participation in one of two identical 3-hour dysphagia-focussed IPE workshops. These cohorts were selected as examination of both curricula indicated closely aligned dysphagia knowledge. Prior to the workshop, students had received uniprofessional introductory education related to the anatomy and physiology of the swallow and attended various clinical placements, though none focussed on dysphagia management. Students were randomly assigned to one workshop and then to small groups comprising 4-5 students, with at least two students from each discipline. Students were permitted to attend (compulsory for SLTs only) even if they chose not to participate in the research. Of the 58 students who were scheduled to attend the workshop, 50 students (25 SLT and 25 MED) attended.

\subsection{Ethical considerations}

Ethical approval was sought and approved through the University's Social Research Ethics Committee and Research \& Postgraduate Affairs Committee.

\subsection{IPE workshops}

The workshops were classroom-based, each facilitated by an SLT who was clinically experienced in dysphagia management and skilled in workshop facilitation. Workshop content development was led by author MC (SLT) alongside discussions with authors HK (SLT) and HH (MED), so workshops were tailored to both cohort's educational needs. Influenced by the principles of Universal Design for Learning (Rose et al., 2006) and Entry Points to Learning (Gardner, 1991), student learning was maximised through active engagement, and teaching methods combined didactic, case-based discussions, and practical group activities. The workshop was organised into four parts. Learning was guided through discussion about causes, presentation, and management of dysphagia, interprofessional roles, ethical considerations, and discussion of real and simulated patient cases. Small group activities and discussions helped to illuminate, exchange, and consolidate knowledge which was shared with the main class. With the exception of patient-facing interaction, the content, learning methods (Appendix 1), and anticipated learning outcomes aligned with recommended IPE framework (Steven et al., 2017) and learning competencies (O'Keefe et al., 2017) (Table 1). Participating students signed a confidentiality document agreeing not to discuss or retain patient-related information beyond the workshop.

\subsection{Workshop evaluation}

This study was evaluated through anonymised paper-based pre- and post-workshop number matched questionnaires. Students were given the questionnaire pairs and allocated time for completion during the workshop. With permission, Anderle et al.'s (2018) questionnaire was adapted and piloted in our previous study with medical students (Kelly et al., unpublished). We further adapted it for this IPE study (Appendix 2). The pre-workshop questionnaire comprised 15 multiple choice, Likert scale and free text questions, which explored the knowledge, previous education, clinical experience, and confidence concerning dysphagia. The post-workshop questionnaire comprised 16 questions to evaluate change in dysphagia knowledge, and gathered opinions on the benefits, advantages, and challenges of IPE as experienced by the students. Students placed completed or blank (if they did not wish to participate) questionnaires in a box when leaving the classroom.

\subsection{Data analysis}

A guide was developed by authors MC and $\mathrm{HK}$ indicating acceptable responses to questionnaire questions 10 (signs of dysphagia) and 12 (role of professionals). Data entry and statistical analyses were carried out by authors SD and OT who were 
Table 1

Workshop Outcome Areas aligned with IPE Framework (Steven et al., 2017) and Learning Competencies (O'Keefe et al., 2017)

\begin{tabular}{|c|c|c|}
\hline $\begin{array}{l}\text { Steven et al. } \\
(2017)\end{array}$ & Workshop Outcome Areas & O'Keefe et al. (2017) \\
\hline $\begin{array}{l}\text { Knowledge for } \\
\text { Practice }\end{array}$ & $\begin{array}{l}\text { Theoretical information related to swallowing and } \\
\text { dysphagia } \\
\text { Discussion around clinical presentations of dysphagia } \\
\text { Recognising the need for a shared knowledge base }\end{array}$ & Describe the areas of practice of other health professions \\
\hline Skills for practice & $\begin{array}{l}\text { Multidisciplinary discussion around formulating client } \\
\text { management plans } \\
\text { Creating clinical products (for example, referral card, } \\
\text { thickening fluids) }\end{array}$ & $\begin{array}{l}\text { Identify opportunities to enhance the care of } \\
\text { patients/clients through the involvement of other } \\
\text { health professionals }\end{array}$ \\
\hline $\begin{array}{l}\text { Patient-centred } \\
\text { approach }\end{array}$ & $\begin{array}{l}\text { Use of patient videos and case histories to support } \\
\text { activities } \\
\text { Consideration of patient quality of life through specific } \\
\text { workshop activities }\end{array}$ & $\begin{array}{l}\text { Plan patient/client care goals and priorities with } \\
\text { involvement of other health professionals }\end{array}$ \\
\hline Team-working & $\begin{array}{l}\text { Creating outcomes that supported patient quality of life, } \\
\text { taking into account differing professional perspectives } \\
\text { Communicating effectively and negotiating appropriate } \\
\text { pathways of care taking into consideration different } \\
\text { professional perspectives }\end{array}$ & $\begin{array}{l}\text { Recognise and resolve disagreements in relation to } \\
\text { patient care that arise from different disciplinary } \\
\text { perspectives } \\
\text { Give timely, sensitive, instructive feedback to } \\
\text { colleagues from other professions, and respond } \\
\text { respectfully to feedback from these colleagues }\end{array}$ \\
\hline Professionalism & $\begin{array}{l}\text { Working with in a respectful way to negotiate patient } \\
\text { outcomes that reflect both professions' perspectives } \\
\text { Presenting information in a format that is accessible to } \\
\text { all parties to facilitate informed decision making }\end{array}$ & $\begin{array}{l}\text { Express professional opinions, competently, confidently, } \\
\text { and respectfully avoiding discipline specific language }\end{array}$ \\
\hline $\begin{array}{l}\text { Ethical approach } \\
\text { to practice }\end{array}$ & $\begin{array}{l}\text { Maintaining Confidentiality } \\
\text { Ethical decision making within the context of patient } \\
\text { information }\end{array}$ & $\begin{array}{l}\text { Recognise and resolve disagreements in relation to } \\
\text { patient care that arise from different disciplinary } \\
\text { perspectives }\end{array}$ \\
\hline $\begin{array}{l}\text { Continuing } \\
\text { professional } \\
\text { development }\end{array}$ & $\begin{array}{l}\text { Evidence based approach to clinical decision making } \\
\text { taking into account the knowledge base of each } \\
\text { profession. }\end{array}$ & $\begin{array}{l}\text { Explain interprofessional practice to patients, client's } \\
\text { families and other professionals (other professionals } \\
\text { only) } \\
\text { Critically evaluate protocols and practices in relation to } \\
\text { interprofessional practice (practices only) }\end{array}$ \\
\hline
\end{tabular}

not involved in the study design or training. Analyses were independently checked for accuracy by author HK. Questionnaire responses were entered into IBM SPSS Statistics for Windows, Version 27 for analysis. Descriptive statistical analyses were carried out to summarise the data and facilitate data interpretation. Data were mainly nominal and ordinal scales with a relatively small sample size. Therefore, inferential statistical analysis of the data included non-parametric measures of Wilcoxon Signed-Rank test for Repeated Measures to compare the means across variables pre- and post-workshop. A $p$-value of 0.05 was considered significant in pre-post (onetail) and between MED-SLT cohorts (two-tail). Any significant results found were further analysed using post-hoc tests (Mann-Whitney U-test) with Bonferroni adjustment to determine any differences between MEDs and SLTs. Spearman's rank-order correlation was carried out to determine the relationship between correct and incorrect answers for dysphagia symptoms and medical conditions. Responses to the comments sections of the questionnaires were transcribed by SD and OT and entered into an Excel sheet. As the dataset primarily comprised one sentence responses, we took a qualitative descriptive approach which according to Sandelowski (2000, p.339) is the "method of choice when straight descriptions of phenomena are desired". SD, OT and HK independently read the responses and undertook content analysis of the data by systematically applying codes, which were then further analysed. The codes were tagged by discipline to allow examination of any differences in experiences between the cohorts. Themes were identified based on the codes that occurred more commonly throughout the data and were agreed with the research team.

\section{Results}

Fifty students attended the IPE workshops and 49 (25 SLT: all female: 24 MED:14 female) completed pre- and post-workshop questionnaires (98\% response rate). 
Table 2

Knowledge about dysphagia

\begin{tabular}{|c|c|c|c|c|}
\hline & \multicolumn{2}{|c|}{$\operatorname{MEDs}(n=24)$} & \multicolumn{2}{|c|}{ SLTs $(n=25)$} \\
\hline & Pre-workshop & Post-workshop & Pre-workshop & Post-workshop \\
\hline Correct sequence of swallow & $21(87.5 \%)$ & $21(87.5 \%)$ & $23(92 \%)$ & $25(100 \%)$ \\
\hline Definition of Dysphagia & $23(95.8 \%)$ & $24(100 \%)$ & $25(100 \%)$ & $25(100 \%)$ \\
\hline Complications of Dysphagia & $21(87.5 \%)$ & $23(95.8 \%)$ & $17(68 \%)$ & $20(80 \%)$ \\
\hline \multicolumn{5}{|l|}{ Symptoms of Dysphagia } \\
\hline - Identified all 8 symptoms* & $5(21 \%)$ & $18(75 \%)$ & $11(44 \%)$ & $20(80 \%)$ \\
\hline \multicolumn{5}{|l|}{ - Incorrect } \\
\hline 0 & 2 & 0 & 0 & 1 \\
\hline $1-2$ & 7 & 1 & 14 & 5 \\
\hline $3-4$ & 10 & 16 & 9 & 14 \\
\hline $5-6$ & 5 & 7 & 2 & 5 \\
\hline \multicolumn{5}{|l|}{ Conditions causing dysphagia } \\
\hline - Identified all 8 conditions* & $14(62.5 \%)$ & $19(79.2 \%)$ & $13(52 \%)$ & $19(76 \%)$ \\
\hline \multicolumn{5}{|l|}{ - Incorrect* } \\
\hline 0 & 12 & 14 & 21 & 18 \\
\hline $1-2$ & 10 & 7 & 4 & 6 \\
\hline $3-4$ & 2 & 2 & 0 & 0 \\
\hline $5-6$ & 0 & 1 & 0 & 1 \\
\hline \multicolumn{5}{|l|}{ Identified signs of dysphagia } \\
\hline - Oral Preparatory/Oral & 1 & 4 & 7 & 4 \\
\hline - Pharyngeal & 22 & 28 & 41 & 39 \\
\hline - Oesophageal & 0 & 1 & 0 & 0 \\
\hline - Other Clinical Signs* & 19 & 25 & 12 & 23 \\
\hline - Incorrect/DK or NR & $15 / 11$ & $9 / 7$ & $9 / 3$ & $10 / 1$ \\
\hline Medication and dysphagia* & $9(37.5 \%)$ & $19(79.2 \%)$ & $5(20 \%)$ & $20(80 \%)$ \\
\hline
\end{tabular}

*statistically significant; DK 'don’t know'; NR 'no response'.

\subsection{Pre-workshop experience of dysphagia}

Pre-workshop, 26/49 students (2/24 MED; 24/25 SLT) reported having previous dysphagia education; 21 students provided details about the nature of education received. SLTs detailed academic education, including lectures and Problem Based Learning $(n=15)$; 1 st year workshops $(n=6)$ and videofluoroscopy swallow observations $(n=4)$, and some listed specific topics $(n=4)$. One third of participants $(10$ MED; 6 SLT) had encountered a patient with dysphagia during clinical placement.

\subsection{Knowledge about dysphagia}

Both cohorts scored highly in identifying the correct sequence of swallowing, dysphagia definition and complications of dysphagia (Table 2). Wilcoxon Signed-Rank tests indicated statistically significant differences between pre- and post-workshop knowledge for the identification of all potential dysphagia symptoms $(\mathrm{z}=4.624, p<0.001)$ and all medical conditions that could cause dysphagia $(\mathrm{z}=3.247$, $p<0.001)$. Post-hoc analysis found no significant difference in knowledge between cohorts $(p>0.025)$.
As students could potentially select every correct and incorrect response (Table 2) a Spearman's rank-order correlation was run to determine the relationship between correct and incorrect answers for dysphagia symptoms and medical conditions. There was a weak positive correlation between correct and incorrect dysphagia symptoms pre-workshop only, which was statistically significant $\left(\mathrm{r}_{\mathrm{s}}(47)=0.340, p=0.17\right)$. No other associations were found.

Students listed signs of dysphagia which we classified into oral preparatory/oral, pharyngeal, and oesophageal swallow phases, and other clinical signs independent of swallow phases, for example, eye tearing or recurrent chest infections. The most reported signs of dysphagia were at the pharyngeal phase for both cohorts pre- $(n=22$ MED; 41 SLT $)$ and post-workshop ( $n=28$ MED; 39 SLT). Other clinical signs reported pre- $(n=19$ MED; 12 SLT $)$ and post-workshop ( $n=25$ MED; 23 SLT) were statistically significant between workshops $(\mathrm{z}=2.621$, $p=0.009$ ) but not between-groups. Fewer oral phase signs were reported pre- $(n=1$ MED; 7 SLT $)$ and post-workshop ( $n=4$ MED; 4 SLT). One MED noted an oesophageal phase sign post-workshop. Incorrect signs were indicated by pre- $(n=15$ MED; 9 
SLT) and post-workshop ( $n=9$ MED; 10 SLT), with 'I don't know/no response' pre- $(n=11$ MED; 3 SLT) reducing post-workshop ( $n=7$ MED; 1 SLT). A statistically significant difference was identified between pre- ( $n=9$ MED; 5 SLT) and post-workshop (19, MED; 20, SLT) knowledge about appropriate medication administration $(\mathrm{z}=4.811, p<0.001)$ but no difference between-groups.

Students rated their confidence in identifying dysphagia. The mean rating pre-workshop was $\overline{\mathrm{x}}=5.08(\mathrm{SD}=1.644)$. When asked what would further increase their confidence, both cohorts $(n=19$ MED; 22 SLT) provided suggestions. The most highly identified need was for education $(n=15 / 19$ MED; SLT 13/22), with SLTs in particular highlighting a desire for practical patient experience $(n=3$ MED; 13 SLT). Two MEDs noted needing more interactions with SLTs. Wilcoxon Signed-Rank tests identified a statistically significant increase in confidence rating post-workshop $(\overline{\mathrm{x}}=7.65(\mathrm{SD}=1.393))$ $(\mathrm{z}=6.014, p<0.001)$. Post-hoc analysis revealed no significant difference between the cohorts. The main educational need highlighted by both cohorts ( $n=13$ MED; 19 SLT) post-workshop was for practical patient experience ( $n=12$ MED; 15 SLT). One SLT indicated the need for further education and two reported feeling more confident following the workshop. As with pre-workshop, 2 MED students noted that more interactions with SLTs would further increase their confidence.

\subsection{Knowledge about interprofessional roles in dysphagia management}

Most students $(n=42 / 49)$ identified SLT as the main profession responsible for dysphagia management pre-workshop which slightly increased post-workshop $(n=47 / 49)$ (Table 3$)$. There was no significant difference between workshops or the two cohorts $(p>0.05)$.

Students rated the relevance of dysphagia to their own clinical practice. Wilcoxon Signed-Rank tests revealed a statistically significant difference between pre- $(\overline{\mathrm{x}} 8.82(\mathrm{SD}=1.481))$, and post-workshop $(\overline{\mathrm{x}}$ $9.12(\mathrm{SD}=1.269))(\mathrm{z}=1.977, p=0.025)$. Post-hoc analysis found a significant difference between the cohorts pre- $(\mathrm{U}=113.5, \mathrm{z}=4.008, p>0.001)$ and post-workshop ( $\mathrm{U}=183, \mathrm{z}=2.686, p=0.004)$ with SLTs recognising greater relevance than MEDs preand post-workshops. Students provided rationales for their ratings pre- $(n=19 / 24$ MED; 20/25 SLT) and post-workshop ( $n=10 / 24$ MED; 16/25 SLT).
The most prominent rationales related to (i) anticipated professional roles pre-workshop ( $n=11$ MED; 16 SLT) and post-workshop ( $n=3$ MED: 11 SLT), followed by (ii) medical conditions, complications and impact pre-workshop ( $n=6$ MED; 2 SLT) and post-workshop ( $n=8 \mathrm{MED}$ ), (iii) part of curriculum pre-workshop ( $n=3$ SLT), (iv) effect on patient quality of life ( $n=2$ MED; 1 SLT) post-workshop and (v) one MED stated pre-workshop that it had 'limited impact' on their clinical role.

Students described the main roles of nine HCPs in dysphagia management (Table 3). Responses were classified into 'dysphagia role', 'extended role' (more general patient care), 'incorrect roles' and 'no response'. Wilcoxon Signed-Rank tests revealed a statistically significant difference between pre- and post-workshops for dysphagia management roles of nursing $(\mathrm{z}=2.111, p=0.033)$, pharmacy $(\mathrm{z}=2.041$, $p=0.032)$, occupational therapy $(\mathrm{z}=2.524, p=0.01)$ and physiotherapy $(\mathrm{z}=3.962, p<0.001)$. Post-hoc analysis highlighted that pre-workshop MEDs were significantly more knowledgeable than SLTs about the pharmacy role $(\mathrm{U}=173, \mathrm{z}=3.041, p=0.002)$. There was no between-group differences post-workshop.

\subsection{Student IPE experiences}

Students rated how beneficial they found the IPE experience $(\overline{\mathrm{x}}=7.86(\mathrm{SD}=2.179))$. Mann-Whitney U-test found no statistical difference between SLT and MED ratings $(p=0.305)$. Three common themes emerged from the qualitative descriptive analysis of student comments (16/24 MED: 18/25 SLT) (Table 4). The first theme 'Learning' provided insight into mixed feelings regarding the information covered in the workshops. Some students reported having prior knowledge of some material, with one SLT commenting that it was "a lot of revision for SLT students". Others identified new areas of learning "helped explain cause \& diagnosis of dysphagia \& treatment options, practical information". Another theme highlighted the 'Communicative Exchange' between the students which was positive overall. Students reported beneficial learning from " $g$ etting other perspectives" in relation to patient care. The final theme 'Interdisciplinary Role' highlighted student learning about each other's role in dysphagia management. Students commented that they "learned $a$ lot about what SLTs do" and "realis[ed] the needs for information of other professionals". 
Table 3

Interdisciplinary Roles in Dysphagia Management

\begin{tabular}{|c|c|c|c|c|}
\hline & \multicolumn{2}{|c|}{ MEDs $(n=24)$} & \multicolumn{2}{|c|}{ SLTs $(n=25)$} \\
\hline & Pre-workshop & Post-workshop & Pre-workshop & Post-workshop \\
\hline \multirow[t]{2}{*}{ Clinical relevance of dysphagia } & $\overline{\mathrm{x}} 8(1.615)$ & $\overline{\mathrm{x}} 8.71(1.268)$ & $\overline{\mathrm{x}} 9.6(.764)$ & $\overline{\mathrm{x}} 9.52(1.159)$ \\
\hline & Range 4-10 & Range 6-10 & Range $8-10$ & Range 5-10 \\
\hline Main professional responsible for dysphagia management & $18(75 \%)$ & $22(91.7 \%)$ & $24(96 \%)$ & $25(100 \%)$ \\
\hline \multicolumn{5}{|l|}{ Dietitian } \\
\hline - Dysphagia role & $20(83.3 \%)$ & $23(95.8 \%)$ & $22(88 \%)$ & $23(92 \%)$ \\
\hline - Extended & 0 & 0 & 0 & 0 \\
\hline - Incorrect/NR & $3 / 1$ & $1 / 0$ & $3 / 0$ & $0 / 2$ \\
\hline \multicolumn{5}{|l|}{ GP } \\
\hline - Dysphagia role & $18(75 \%)$ & $20(83.3 \%)$ & $18(72 \%)$ & $22(88 \%)$ \\
\hline - Extended & 0 & 2 & 1 & 0 \\
\hline - Incorrect/NR & $1 / 5$ & $0 / 2$ & $1 / 5$ & $1 / 2$ \\
\hline \multicolumn{5}{|l|}{ Nurse* } \\
\hline - Dysphagia role & $19(79.2 \%)$ & $21(87.5 \%)$ & $16(64 \%)$ & $21(84 \%)$ \\
\hline - Extended & 1 & 1 & 1 & 1 \\
\hline - Incorrect/NR & $1 / 3$ & $1 / 1$ & $1 / 7$ & $1 / 2$ \\
\hline \multicolumn{5}{|l|}{ Occupational Therapist* } \\
\hline - Dysphagia role & $12(50 \%)$ & $19(79.2 \%)$ & $19(76 \%)$ & $23(92 \%)$ \\
\hline - Extended & 2 & 1 & 0 & 0 \\
\hline - Incorrect/NR & $0 / 10$ & $3 / 1$ & $0 / 6$ & $0 / 2$ \\
\hline \multicolumn{5}{|l|}{ Pharmacist* } \\
\hline - Dysphagia role & $14(58.3 \%)$ & $14(58.3 \%)$ & $4(16 \%)$ & $15(60 \%)$ \\
\hline - Extended & 6 & 9 & 14 & 8 \\
\hline - Incorrect/NR & $0 / 4$ & $0 / 1$ & $0 / 7$ & $0 / 2$ \\
\hline \multicolumn{5}{|l|}{ Physician } \\
\hline - Dysphagia role & $12(50 \%)$ & $12(50 \%)$ & $2(8 \%)$ & $\mathbf{0}$ \\
\hline - Extended & 2 & 4 & 5 & 3 \\
\hline - Incorrect/NR & $3 / 7$ & $6 / 2$ & $2 / 16$ & $12 / 10$ \\
\hline \multicolumn{5}{|l|}{ Physiotherapist* } \\
\hline - Dysphagia role & $8(33.3 \%)$ & $17(70.9 \%)$ & $2(8 \%)$ & $12(48 \%)$ \\
\hline - Extended & 1 & 4 & 10 & 7 \\
\hline - Incorrect/NR & $6 / 9$ & $3 / 0$ & $3 / 10$ & $3 / 3$ \\
\hline \multicolumn{5}{|l|}{ Radiologist } \\
\hline - Dysphagia role & $16(66.7 \%)$ & $21(87.5 \%)$ & $23(96 \%)$ & $23(92 \%)$ \\
\hline - Extended & 1 & 0 & 0 & 0 \\
\hline - Incorrect/NR & $3 / 4$ & $3 / 0$ & $1 / 1$ & $0 / 2$ \\
\hline \multicolumn{5}{|l|}{ Speech and Language Therapist } \\
\hline - Dysphagia role & $18(75 \%)$ & $23(95.8 \%)$ & $25(100 \%)$ & $23(92 \%)$ \\
\hline - Extended & 2 & 1 & 0 & 0 \\
\hline - Incorrect/NR & $1 / 3$ & $0 / 0$ & $0 / 0$ & $0 / 2$ \\
\hline
\end{tabular}

*statistically significant; NR- no response.

\subsection{Challenges and advantages of IPE}

Students documented challenges and advantages of IPE. Five common themes highlighted challenges experienced during IPE ( $n=18 / 24$ MED; $17 / 25$ SLT) (Table 5). The first theme 'Prior Knowledge' emphasised that "different knowledge levels" pre-workshop was considered challenging (6/18 MED; 8/17 SLT). Despite the inclusion of icebreakers and small group tasks, 'Group Familiarity' was noted to be a challenge of IPE by both cohorts (7/18 MED; 4/17 SLT) with several students stating that "meeting new people" and "getting to know others" was challenging. The theme of 'Communicative Exchange' was identified as students (11/18 MED; 8/17 SLT) reported struggling with conflicting opinions and perspectives. For instance, students reported "clashing points of view" and that "open discussion is difficult". This negative perception extended to 'Patient Care' where some students (4/18 MED; 6/17 SLT) believed there were "differing priorities for the patient" between disciplines. A lack of understanding about 'Interdisciplinary Roles' was highlighted as challenging (3/18 MED; 8/17 SLT) with students commenting that "understanding a new discipline" was difficult. Several MEDs (6/18) commented that the timing of the workshop was burdensome "take[ing] up a lot of time in final year". 
Table 4

Benefits of IPE

\begin{tabular}{ll}
\hline Theme identified & Illustration of theme \\
\hline Learning & "didn't know previously about different \\
types of fluids, DOSS score" (MED) \\
"this was a fantastic learning opportunity" \\
(SLT) \\
"though we had most of the information \\
already it was a good refresher" (SLT) \\
"good being with med students; good to hear \\
their side" (SLT) \\
Exchange & "talking in a group setting is v. beneficial" \\
& (MED) \\
"we learned from each other" (SLT) \\
"wole \\
"was good to get an understanding of the \\
role of the SLT" (MED) \\
"important to link in with other fields as \\
everyone plays an important role in \\
dysphagia management" (SLT) \\
"realising the needs for information of other \\
professionals" (SLT)
\end{tabular}

Table 5

Challenges of IPE

\begin{tabular}{ll}
\hline Theme identified & Illustration of theme \\
\hline Prior Knowledge & "different knowledge levels" (MED) \\
& "different levels of knowledge before \\
& workshop" (SLT) \\
Group Familiarity & "intimidating" (SLT) \\
& "lack of familiarity" (SLT) \\
& "not knowing each other" (MED) \\
"differences of opinion on ethical issues" & (MED) \\
Exchange & "not understanding each other" (SLT) \\
& "conflicting priorities for patient" (SLT) \\
Patient Care & "too many procedures may mishandle \\
& patient management" (MED) \\
& "not always going to be able to do what you \\
think is best, different recommendations" & (SLT) \\
"different goals/ interests" (MED)
\end{tabular}

Five themes were identified as advantages of IPE (24 MED; 22 SLT) (Table 6). The first theme 'Knowledge' (14/24 MED; 6/22 SLT) highlighted the benefits of "sharing knowledge" noting that the disciplines were "knowledgeable in different areas". While the theme of 'Communicative Exchange' was previously noted to be a challenge, students (14/24 MED; 16/22 SLT) noted benefits of "exchang[ing] ideas" and "acknowledging different perspectives". The advantage of IPE for 'Patient Care' was identified with both cohorts (7/24 MED; 8/22 SLT) remarking that IPE "aids holistic care" with "real world application". 'Team-Work' was another identified theme where students highlighted that IPE fosters
Table 6

Advantages of IPE

\begin{tabular}{|c|c|}
\hline Theme identified & Illustration of theme \\
\hline Knowledge & $\begin{array}{l}\text { "learn about another medical field" (MED) } \\
\text { "learning from each other - all are } \\
\text { knowledgeable in different areas" (SLT) }\end{array}$ \\
\hline $\begin{array}{l}\text { Communicative } \\
\text { Exchange }\end{array}$ & $\begin{array}{l}\text { "get to see things from other perspectives" } \\
\text { (SLT) } \\
\text { "seeing things from a different point of } \\
\text { view" (MED) } \\
\text { "broader outlook" (SLT) }\end{array}$ \\
\hline Patient Care & $\begin{array}{l}\text { "having different perspectives to add to } \\
\text { patient care" (MED) } \\
\text { "get different perspectives on clinical issues" } \\
\text { (MED) } \\
\text { "holistic client -view" (SLT) }\end{array}$ \\
\hline Team-Work & $\begin{array}{l}\text { "learn how to work together" (SLT) } \\
\text { "learning to work together as a team" (MED) } \\
\text { "get to know other members of your team" } \\
\text { (SLT) }\end{array}$ \\
\hline $\begin{array}{l}\text { Interdisciplinary } \\
\quad \text { Role }\end{array}$ & $\begin{array}{l}\text { "knowledge on what other's roles are" (SLT) } \\
\text { "more aware of MDT work on dysphagia" } \\
\text { (MED) } \\
\text { "the importance of the MDT" (SLT) }\end{array}$ \\
\hline
\end{tabular}

teamworking by "build[ing] rapport with other specialties" and "encourag[ing] cooperation". The final theme 'Interdisciplinary Roles' identified by both cohorts (18/24 MED; 14/22 SLT) highlighted the importance of "learning about [the] role of another speciality" as being an advantage of IPE.

\section{Discussion}

IPE is essential for the awakening of healthcare students to the need for collaborative working to enhance patient care (WHO, 2010). Studies have demonstrated a positive attitude by students towards IPE (Berger-Estilita et al., 2020) with some evidence for enhanced patient health outcomes (Oosterom et al., 2019; Shrader et al., 2018). Our study explored MED and SLT student perspectives about their experience following one 3-hour classroom-based IPE workshop that focussed on a complex health condition that both disciplines would manage collaboratively when qualified. Notably, we assessed knowledge acquired from this shared learning which largely aligned with recommended IPE framework (Steven et al., 2017) and learning competencies (O'Keefe et al., 2017).

\subsection{Knowledge and confidence around dysphagia management}

The education intervention had a significant positive effect on the learning of both student cohorts. 
Prior to the workshop, most students understood the correct swallow phases and definition of dysphagia. However, knowledge pertaining to the symptoms and medical causes of dysphagia, and medication administration showed statistically significant improvement following active shared learning, for both cohorts. Importantly, students reported having more confidence in identifying a patient with dysphagia following the workshop. While most students recognised the SLT as primarily responsible for dysphagia management, knowledge regarding the roles of other HCPs involved in dysphagia care increased significantly post-workshop, in particular nursing, occupational therapy, pharmacy, and physiotherapy. While SLTs rated the relevance of dysphagia more highly than MEDs, there was a significant positive shift in acknowledging its relevance to clinical practice post-workshop by both cohorts. This fostered important professional awareness given that a team approach to dysphagia management is considered optimal for positive patient outcomes (Aoki et al., 2016; Clavé \& Shaker, 2015; Middleton et al., 2011).

\subsection{Student experience of IPE}

Both cohorts rated their IPE experience overall as beneficial and highlighted advantages in relation to the acquisition and sharing of knowledge. Even so, student comments sometimes appeared contradictory. There was a sense of them wrestling with the challenges of IPE while simultaneously appreciating its benefits. While students welcomed the opportunity to hear the perspectives of the other discipline, they found it challenging to negotiate conflicting opinions and manage the communicative exchange, with one MED asking, "Who captains the ship"? Perhaps this is part of the essential growing process, shifting beyond what Eichorn et al. (2020) term as the 'uniprofessional lens' and broadening their understanding and appreciation of their future clinical selves within an interprofessional team. This shift can be challenging for students who, according to Vuurberg et al. (2019, p.158), may have previously engaged in a "socialisation process and mono-disciplinary learning experiences [that] enforce professional boundaries and silos". This raises the complex question regarding the timing of IPE in healthcare curricula. On one hand, students must acquire specialist knowledge about their discipline and develop their own professional identity, whilst also learning how to work collaboratively with other disciplines. There is no clear-cut solution as various dynamics need consideration, such as age, mature students versus school leavers, prior knowledge, and previous teamwork experience (Anderson \& Thorpe, 2008).

According to Reeves et al. (2016) for effective learning, IPE should ideally be carried out in a context that reflects the students' future practice. Cox et al. (2016) also raise concerns that most IPE is classroom-based and recommends that to align IPE and healthcare services, IPE should relocate to clinical environments and include the patient, family, and caregiver experiences. However, our study and others (Anderson et al., 2011; Morison et al., 2003; Vuurberg et al., 2019) have demonstrated positive outcomes from classroom-based learning. Our classroom-based IPE workshop provided opportunities for teamwork activities and shared learning about a complex health condition. As our materials included real and simulated patient data with corresponding authentic ethical challenges, students were exposed to experiences requiring conflict resolution in interprofessional groups. Additionally, substantial clinically relevant knowledge acquisition is evidence of the value of IPE in an educational setting. However, our students emphasised the need for hands-on dysphagia-focussed clinical practice and considered it fundamental to improving their confidence in dysphagia management. Morison et al. (2003) report student preference for combining classroom and ward-based learning, considered particularly effective for supporting students to feel part of a clinical team. Anderson et al. (2011) found that IPE in clinical settings had a greater impact on student learning than classroom-based alone. Bringing IPE to the patients, or the patients to the classroom would further enhance clinical learning, where students can experience teamwork in action. This patient-facing interaction could also facilitate meeting relevant patient-related IPE learning competencies (O'Keefe et al., 2017).

\subsection{Limitations and future research}

Questionnaire comments provided several insights into student IPE experiences. Some students reported a negative impact on discussions due to different prior knowledge around dysphagia. Future IPE could take a flipped-classroom approach where students would view cross-disciplinary learning materials to ensure an equitable knowledge base before IPE engagement. We erroneously assumed that student experience in working effectively in within-discipline groups 
would automatically transfer to cross-disciplinary learning. Machin et al. (2019) note student groups commonly feel anxious about revealing their potential lack of knowledge in IPE. Our findings concur, suggesting the need for preparatory support regarding expectations to reduce vulnerability when sharing knowledge with other disciplines. Reflective of the learning approach at our teaching hospital and university, students learn about dysphagia management from clinically experienced SLTs. However, Morison et al. (2003) found their students relied on faculty from their own discipline for encouragement in engaging with IPE. Therefore, students may benefit from having workshop facilitators from each discipline, modelling interprofessional collaboration in their teaching (Anderson et al., 2011). Finally, though potentially logistically challenging (Barrett et al., 2003), future IPE could expand the range of disciplines included, for example, dietetics, pharmacy, and other HCPs, thus providing learning opportunities more reflective of interprofessional discussions of complex dysphagia cases. This would provide a larger sample size but importantly better prepare healthcare students to become a 'collaborative practice-ready' workforce (WHO, 2010).

\section{Conclusion}

The management of dysphagia, a complex and pervasive health condition, requires interprofessional collaboration to enhance patient health outcomes, therefore HCPs should be educated at undergraduate level in preparation for collaborative patient care. Our study uniquely demonstrated that one 3-hour classroom-based IPE workshop increased student knowledge about dysphagia and fostered an appreciation of the importance of interprofessional team roles. IPE as a teaching method was valued by students which challenged them in ways that uniprofessional education could not, for instance, cross-disciplinary patient case discussions. The inclusion of patientfacing clinical activities would provide further valuable insight into interdisciplinary collaboration and develop more confidence in working with this health condition.

\section{Acknowledgments}

This project was funded by INHED Education and Research Grant Scheme 2019. We would also like to extend our thanks to Adrian Bradley who facilitated one of the IPE workshops.

\section{Conflict of interest}

The authors have no conflict of interest to report. Given her role as an Editorial Board Member, Helen Kelly had no involvement nor access to information regarding the peer review of this article.

\section{Supplementary material}

Appendices are available in the electronic version of this article: https://dx.doi.org/10.3233/ACS210027.

\section{References}

Anderle, P., Rech, R.S., Pasqualeto, V.M., \& de Goulart, B.N.G. (2018). Knowledge of the medical and nursing teams about the management of oral medications in hospitalized adult dysphagic patients. Audiology Communication Research, 23, e1933. https://doi.org/10.1590/2317-6431-2017-1933

Anderson, J.E., Ateah, C., Wener, P., Snow, W., Metge, C., MacDonald, L., Fricke, M., Ludwig, S., \& Davis, P. (2011). Differences in pre-licensure interprofessional learning: classroom versus practice settings. Journal of Research in Interprofessional Practice and Education, 2(1). https://doi.org/10.22230/ jripe.2011v2n1a54

Anderson, E.S., \& Thorpe L.N. (2008). Early Interprofessional Interactions: Does Student Age Matter? Journal of Interprofessional Care, 22(3), 263-282. https://doi.org/10.1080/135618 20802054689

Aoki, S., Hosomi, N., Hirayama, J., Nakamori, M., Yoshikawa, M., Nezu, T., Kubo, S., Nagano, Y., Nagao, A., Yamane, N., Nishikawa, Y., Takamoto, M., Ueno, H., Ochi, K., Maruyama, H., Yamamoto, H., Matsumoto, M., \& Hiroshima University Hospital Stroke Swallowing Team. (2016). The Multidisciplinary Swallowing Team Approach Decreases Pneumonia Onset in Acute Stroke Patients. PLoS ONE, 11(5). https://doi.org/0.1371/journal.pone.0154608

Azzam, M., Puvirajah, A., Girard, M., \& Grymonpre, R.E. (2021). Interprofessional education-relevant accreditation standards in Canada: a comparative document analysis. Hum Resour Health, 19(66). https://doi.org/10.1186/s12960-021-00611-1

Baijens, L.W., Clavé, P., Cras, P., Ekberg, O., Forster, A., Kolb, G.F., Leners, J.-C., Masiero, S., Mateos-Nozal, J., Ortega, O., Smithard, D.G., Speyer, R., \& Walshe, M. (2016). European Society for Swallowing Disorders - European Union Geriatric Medicine Society white paper: oropharyngeal dysphagia as a geriatric syndrome. Clinical Interventions in Aging, 11, 14031428.

Barrett, G., Greenwood, R., \& Ross, K. (2003). Integrating interprofessional education into 10 health and social care pro- 
grammes. Journal of Interprofessional Care, 17(3), 293-301. https://doi.org/10.1080/1356182031000122915

Berger-Estilita, J., Fuchs, A., Hahn, M., Chiang, H., \& Greif, R. (2020). Attitudes towards Interprofessional education in the medical curriculum: a systematic review of the literature. $B M C$ Medical Education, 20(254). https://doi.org/10.1186/s12909020-02176-4

Burford, B., Greig, P., Kelleher, M., Merriman, C., Platt, A., Richards, E., Davidson, N., \& Vance, G. (2020). Effects of a single interprofessional simulation session on medical and nursing students' attitudes toward interprofessional learning and professional identity: a questionnaire study. BMC Medical Education, 20(65). https://doi.org/10.1186/s12909-0201971-6

Cabre, M., Serra-Prat, M., Palomera, E., Almirall, J., Pallares, R., \& Clavé, P. (2010). Prevalence and prognostic implications of dysphagia in elderly patients with pneumonia. Age and Ageing, 39, 39-45. https://doi.org/10.1093/ageing/afp100

Clave, P., \& Shaker, R. (2015). Dysphagia: current reality and scope of the problem. Nature Reviews: Gastroenterology \& Hepatology, 12, 259-270. https://doi.org/10.1038/nrgastro. 2015.49

CORU. (2018). Speech and Language Therapists Registration Board: Criteria for Education and Training Programmes. CORU.

Cox, M., Cuff, P., Brandt, B., Reeves, S., \& Zierler, B. (2016). Measuring the impact of interprofessional education on collaborative practice and patient outcomes. Journal of Interprofessional Care, 30(1), 1-3. https://doi.org/10.3109/13561820.2015.11 11052

Eichorn, N., Caplan, J., Levy, M., Zarn, M., Moncrieff, D., Sposto, C., \& Hoffman, J.E. (2020). Breaking the ice: Use of music improvisation to facilitate interprofessional communication. Journal of Interprofessional Education \& Practice, 21. https://doi.org/10.1016/j.xjep.2020.100379

Farpour, S., Farpour, H.R., Smithard, D., Kardeh, B., Ghazaei, F., \& Zafarghasempour, M. (2019). Dysphagia Management in Iran: Knowledge, Attitude and Practice of Healthcare Providers. Dysphagia, 34, 105-111. https://doi.org/10.1007/s00455-0189919-2

Frowen, J., Hughes, R., \& Skeat, J. (2020). The prevalence of patient-reported dysphagia and oral complications in cancer patients. Supportive Care in Cancer, 28, 1141-1150. https:// doi.org/10.1007/s00520-019-04921-y

Gardner, H. (1991). The Unschooled Mind. Basic Books.

HCPC. (2017). Standards of education and training guidance. Health and Care Professions Council.

Ikeda, M., Brown, J., Holland, A.J., Fukuhara, R., \& Hodges, J. (2002). Changes in appetite, food preference, and eating habits in frontotemporal dementia and Alzheimer's disease. $J$ Neurol Neurosurg Psychiatry, 73(4), 371-376. https://doi.org/ 10.1136/jnnp.73.4.371

Interprofessional Education Collaborative Expert Panel. (2011). Core competencies for Interprofessional collaborative practice: Report of an expert panel.

Kalf, J.G., de Swart, B.J.M., Bloem, B.R., \& Munneke, M. (2012). Prevalence of oropharyngeal dysphagia in Parkinson's disease: A meta-analysis. Parkinsonism and Related Disorders, 18, 311-315. https://doi.org/10.1016/j.parkreldis.2011.11.006

Kelly, H., Grealy, A., Daly, Á., Bradley, A., Keohane, S., \& Brosnan, S. (n.d.). Investigating the dysphagia knowledge of final year medical students. Unpublished.
Machin, L.L., Bellis, K.M., Dixon, C., Morgan, H., Pye, J., Spencer, P., \& Williams, R.A. (2019). Interprofessional education and practice guide: designing ethics-orientated interprofessional education for health and social care students. Journal of Interprofessional Care, 33(6), 608-618. https://doi.org/ 10.1080/13561820.2018.1538113

Martino, R., Foley, N., Bhogal, S., Diamant, N., Speechley, M., \& Teasell, R. (2005). Dysphagia After Stroke: Incidence, Diagnosis, and Pulmonary Complications. Stroke, 36, 2756-2763. https://doi.org/10.1161/01.STR.0000190056.76543.eb

Middleton, S., McElduff, P., Ward, J., Grimshaw, J.M., Dale, S., \& D'Este, C. et al. (2011). Implementation of evidencebased treatment protocols to manage fever, hyperglycaemia, and swallowing function in acute stroke (QASC): a cluster randomised controlled trial. The Lancet, 378(9804), 1699-1706.

Morison, S., Boohan, M., Jenkins, J., \& Moutray, M. (2003). Facilitating undergraduate interprofessional learning in healthcare: comparing classroom and clinical learning for nursing and medical students. Learning in Health and Social Care, 2(2), 92-104. https://doi.org/10.1046/j.1473-6861.2003.00043.x

Nasir, J., Goldie, J., Little, A., Banerjee, D., \& Reeves, S. (2017). Case-based interprofessional learning for undergraduate healthcare professionals in the clinical setting. Journal of Interprofessional Care, 31(1), 125-128. https://doi.org/10.1080/ 13561820.2016.1233395

Nisbet, G., Hendry, G.D., Rolls, G., \& Field, M.J. (2008). Interprofessional learning for pre-qualification health care students: An outcomes-based evaluation. Journal of Interprofessional Care, 22(1), 57-68. https://doi.org/10.1080/13561820701722386

O'Keefe, M., Henderson, A., \& Chick, R. (2017). Defining a set of common interprofessional learning competencies for health profession students. Medical Teacher, 39(5), 463-468. https://doi.org/10.1080/0142159X.2017.1300246

Oosterom, N., Floren, L.C., ten Cate, O., \& Westerveld, H.E. (2019). A review of interprofessional training wards: Enhancing student learning and patient outcomes. Medical Teacher, 41(5), 547-554. https://doi.org/10.1080/0142159X.2018.15 03410

Reeves, S., Fletcher, S., Barr, H., Birch, I., Boet, S., Davies, N., McFadyen, A., Rivera, J., \& Kitto, S. (2016). A BEME systematic review of the effects of interprofessional education: BEME Guide No. 39. Medical Teacher, 38(7), 656-668. https://doi.org/10.3109/0142159X.2016.1173663

Rose, D.H., Harbour, W.S., Johnston, C.S., Daley, S.G., \& Abarbanell, L. (2006). Universal Design for Learning in Postsecondary Education: Reflections on Principles and their Application. Journal of Postsecondary Education and Disability, 19(2), 135-151.

Sandelowski, M. (2000). Whatever happened to qualitative description? Research in Nursing \& Health, 23(4), 334-340. https://doi.org/10.1002/1098-240x(200008)23:4<334::aidnur9>3.0.co;2-g

Shrader, S., Jernigan, S., Nazir, N., \& Zaudke, J. (2018). Determining the impact of an interprofessional learning in practice model on learners and patients. Journal of Interprofessional Care. https://doi.org/10.1080/13561820.2018.1513465

Spaulding, E.M., Marvel, F.A., Jacob, E., Rahman, A., Hansen, B. R., Hanyok, L.A., Martin, S.S., \& Han, H.-R. (2019). Interprofessional education and collaboration among healthcare students and professionals: a systematic review and call for action. Journal of Interprofessional Care. https://doi.org/10.1080/ 13561820.2019.1697214 
Steven, K., Howden, S., Mires, G., Rowe, I., Lafferty, N., Arnold, A., \& Strath, A. (2017). Toward interprofessional learning and education: Mapping common outcomes for prequalifying healthcare professional programs in the United Kingdom. Medical Teacher, 39(7), 720-744. https://doi.org/10.1080/ 0142159X.2017.1309372561820.2018.1513465

Suttrup, I., \& Warnecke, T. (2016). Dysphagia in Parkinson's Disease. Dysphagia, 31, 24-32. https://doi.org/10.1007/s00455015-9671-9

Vuurberg, G., Vos, J., Christoph, L., \& de Vos, R. (2019). The effectiveness of interprofessional classroom-based education in medical curricula: A systematic review. Journal of Interprofessional Education \& Practice, 15, 157-167. https://doi.org/ 10.1016/j.xjep.2019.01.007
Wheeler, S., Valentino, A.S., Liston, B.W., Li, J., \& McAuley, J.W. (2019). A team-based learning approach to interprofessional education of medical and pharmacy students. Currents in Pharmacy Teaching and Learning, 11, 1190-1195. https://doi.org/ 10.1016/j.cptl.2019.07.010

World Health Organization. (2010). Framework for action on interprofessional education and collaborative practice. World Health Organization. Retrieved from https://www.who.int/hrh/ resources/framework_action/en/ 